\title{
Governing the transition to a biofuels economy in the US and EU: accommodating value conflicts, implementing uncertainty
}

\author{
Adrian Kay $^{\mathrm{a}}$ and Robert Ackrill ${ }^{\mathrm{b} * 1}$ \\ ${ }^{a}$ Crawford School of Public Policy, Australian National University, Canberra,
}

Australia

${ }^{\mathrm{b}}$ Division of Economics, Nottingham Business School, Nottingham Trent University, Nottingham, UK

* corresponding author

\begin{tabular}{|l|l|}
\hline Dr Adrian Kay & $\begin{array}{l}\text { Professor Robert Ackrill } \\
\text { Crawford School of Public Policy }\end{array}$ \\
No 132 Lennoxion of Economics \\
Nottingham Business School \\
The Australian National University & Nottingham Trent University \\
Canberra, ACT 0200 & Nurton Street \\
Australia & NG1 4BU, UK \\
E-mail: adrian.kay@,anu.edu.au & E-mail: $\underline{\text { robert.ackrill@,ntu.ac.uk }}$ \\
Tel: $+61(0) 261254119$ & Tel $+44(0) 1158484234$ \\
& Fax: $+44(0) 1158488010$
\end{tabular}

\footnotetext{
${ }^{1}$ The authors gratefully acknowledge the financial support of the ESRC, Small Research Grant RES-00022-3607. They thank the policy-makers, industry officials and experts interviewed who gave their time so freely and willingly, but for whom anonymity was a condition of access. Ackrill thanks the Centre for European Studies, Australian National University, for hospitality and support in the final stages of writing this paper. The authors thank the Editors and referees for their comments. The usual disclaimer applies.
} 


\title{
Governing the transition to a biofuels economy in the US and EU: accommodating value conflicts, implementing uncertainty
}

\begin{abstract}
The scale of the ambition to decouple emissions growth from energy consumption runs counter to decades of debates and literatures on the limits of government. Transport biofuels are an early and influential case of the policy capacity challenge in the transition to low-carbon economies. The case stands analytically for the policymaker's dilemma of maintaining long-term policy goals as credible commitments, despite the flexibility and adaptability in policy-making required to achieve them under high political, technological and market uncertainty. This paper compares US and EU biofuels policy processes in these terms. It reveals an intertemporal choice embedded in biofuels policies which tests the capacity to account for future benefits from a low carbon future in current policy processes; if the pathway to their achievement is uncertain and politically contested in the implementation phase, then future benefits may be heavily discounted, shortening policy-maker horizons and rendering the transition process politically vulnerable.
\end{abstract}

\section{Keywords}

Biofuels policy, firewalling, policy capacity, policy dynamics, renewable energy, value conflict 


\section{Introduction}

The challenge policy-makers face as they seek to decouple emissions growth from energy consumption in the economy is formidable. Recent policy efforts to increase the production and use of transport biofuels in the EU and US are early exemplars of the challenge. The transport sector is central to the goal of reducing carbon emissions across the economy: it is highly dependent on fossil fuels; and is projected to be the major source of increases in $\mathrm{CO} 2$ emissions in coming decades (see, inter alia, Kavalov, 2004). Further, biofuels are a 'most likely' case in the range of measures required for a successful transition to a low carbon economy: production technologies are well-understood, the existing transport energy infrastructure can be used, major domestic agricultural producers will benefit, and only limited lifestyle changes currently are needed from consumers. If, given these advantages, biofuels policy is vulnerable politically, then policy instruments directed at sectors with more challenging low carbon transition paths are likely to struggle to achieve their objectives.

Policy-makers face three distinct but inter-related sources of uncertainty as they seek to develop biofuels markets. Market uncertainty exists for all commodities; for biofuels it is particularly acute because the EU and US are seeking to develop biofuels production and consumption on an unprecedented scale, from small beginnings; and because biofuels markets overlap agricultural commodity and energy markets, which are volatile and which thus transmit price uncertainty to biofuels markets.

Second, there are technological uncertainties. Biofuels can be identified as 'conventional' or first generation (1G), derived from agricultural feedstocks; or 
'advanced', derived from non-food inputs. As elaborated below, advanced biofuels can help reduce or avoid the downsides of $1 \mathrm{G}$ biofuels. The problem is that, as yet, there is virtually no large-scale commercial production of advanced biofuels; even though, in many cases, the technologies are understood at the laboratory or demonstration-plant scale.

Third, there are political uncertainties. Given the economic and technological commitments to expanding biofuels markets over time, current policies need to commit future policy preferences regarding the transition to a low-carbon future which includes biofuels. The challenge is to develop credible and time-consistent biofuels policies.

This paper represents an empirical contribution to the Special Issue analysing the New Politics of Food and Agriculture; specifically, an analysis of the challenges policy-makers and policy actors face, in seeking to establish a market for biofuels. Our paper draws on a unique dataset, derived from extensive interviews and seminars with elite policy actors. ${ }^{2}$ This contemporary insider information enables a singular analysis and contribution to the literature on the challenges of biofuels marketcreation, and of setting and maintaining a course towards ambitious far-distant policy goals. Crucially, it allows for a timely analysis of a new, fast-moving and politicallycontested policy domain.

\footnotetext{
${ }^{2}$ Our first round of interviews, through 2010, involved semi-structured interviews with 35 individuals, spread roughly equally across Brussels, Washington and Brasilia. All were in senior positions. Most were civil servants in key agencies/departments (notably energy, agriculture and environment), with a very small number of politicians and 5 senior industry representatives. Our return visits, in 2011 included three additional interviews under similar conditions, plus feedback and discussion in seminars, with a further 20 or so senior civil servants, in those same agencies/departments. Most interviews were recorded then transcribed, but a few interviewees asked that we not record, but take handwritten notes.
} 
This paper employs the concept of policy capacity (see, inter alia, Painter and Pierre, 2005), as a heuristic device, by which we can describe and structure our data and empirical analysis of EU and US biofuels policies: it is not intended as a contribution to the analytical literature on policy capacity. The paper, in Section 2, identifies five dimensions of policy capacity that are, primae facie, challenged by the transition to a biofuels economy. These are grounded in the particular concerns of agricultural policy. These are therefore purposeful, extracted with the specific aims of assisting the narrative of the policy-design and policy-implementation; and helping adumbrate the critical temporally-sensitive aspects of biofuels policy-making.

These temporal challenges for biofuels policies arise because $1 \mathrm{G}$ and advanced biofuels embody different values. Whilst both can promote energy security, $1 \mathrm{G}$ biofuels offer market opportunities for farmers and immediate incorporation into fuels to tackle energy security and climate concerns. Advanced biofuels offer greater emissions reductions, whilst avoiding food versus fuel clashes and reducing land use conflicts. The challenge for policy-makers is to facilitate the private sector in their efforts to get advanced biofuels to market.

To remain credible and time-consistent, biofuels policies which are based on $1 \mathrm{G}$ biofuels but promise advanced biofuels in the future must eventually see them delivered. Managing the inter-temporal separation of these elements is thus critical to avoiding values-based clashes over biofuels policy. In the long term, if advanced biofuels are not delivered to market, their supporters will cease to back a biofuels policy delivering only $1 \mathrm{G}$ biofuels: future benefits will be heavily discounted, shortening policy-maker horizons and rendering the overall transition process politically vulnerable. Thus, despite the fast-moving nature of biofuels policy, our 
analysis provides a forward-looking perspective on the ongoing challenges policymakers are expected to face.

Section 2 outlines these dimensions of policy capacity. Section 3 begins with a short background to EU and US biofuels policy design and implementation over the last decade. It then presents our analysis of qualitative data from semi-structured interviews recently undertaken with leading policy actors in both jurisdictions, and in Brazil, to present a detailed 'casing' of biofuels policy-making. Section 4 concludes.

\section{Policy capacity for the transition to a low carbon economy}

Policy capacity is variously defined in the literature, and enjoys currency because it encompasses two linked governance concerns; (i) the recognition of increasingly complex interdependence in the international economy imposing limits on conventional command-and-control governing strategies, and (ii) a prominent discourse about the development of steering capacity as an essential feature of effective, contemporary governing (Dror, 2001).

The salience of policy capacity is related to the oft-invoked view that governments 'steer and do not row' in the contemporary international political economy. Parsons (2004, page 44) develops a nautical version of the steering metaphor, arguing that map-making and navigating are core elements of the capacity to govern, "the ability to chart the voyage, plot coordinates, set direction and take a long term view - in short, to navigate."

The academic literature on policy capacity offers subtle definitional variety. An indicative selection includes the ability of governments to make intelligent policy choices (Painter and Pierre, 2005); to scan the horizon and set strategic policy 
directions (Howlett and Lindquist, 2004); the faculty to weigh and assess the implications of policy alternatives (Bakvis, 2000), as well as aptitude in making the effective use of appropriate knowledge in policy-making (Parsons, 2004; Bakvis and Aucoin, 2005). Davis (2000) makes specific reference to the ability of governments to implement preferred choices of action as well as decide upon them. Parsons (2004) describes this as the 'weaving' function of modern governments, the ability to weave together the multiplicity of organisations and interests to form a coherent policy fabric which can survive the politics of policy implementation.

Travel-based metaphors are particularly pertinent to biofuels policy. In both the EU and US, policies have been agreed which, in little more than a decade, require a considerable expansion of biofuels production and consumption. Moreover, delivery requires the active participation of private sector and non-state actors: the public sector is not able to deliver biofuels to market, yet expects to be able to direct private sector actors to do so. We now introduce briefly five dimensions to policy capacity, by which policy-makers seek to achieve this

\subsection{Value agreement capacity}

To deliver a policy that lasts, policy-makers will seek a broad-based coalition of support around the values that motivate policy. The advocacy coalitions literature (Sabatier, 1999; Sabatier and Jenkins-Smith, 1993) views policy capacity in terms of governments being able to introduce significant policy changes without suffering societal backlash and electoral defeat. However, as contributions in Adger and Jordan (2009) suggest, this may be an unrealistic standard in the governance of sustainability, which is marked by conflicting or incommensurable values and sharply divided public 
attitudes. In the transition to a low carbon transport fuel mix, the capacity of policymakers is better understood as managing the value conflicts inevitably arising as the policy is implemented.

\subsection{Selection capacity}

This dimension is the varying ability of governments to forge authoritative policy choices which commit relevant actors, notably private enterprises in the case of biofuels, to implementing policy alternatives. With advanced biofuels, this requires the commercialisation of technologies. Further, as the environmental policy literature suggests, the goal of sustainability imposes requirements across a wide set of cognate policy areas. This leaves governments with the challenge of coherent, joined-up policy making in a context where power may be diffuse, political consensus difficult to achieve and implementation across time requires strong co-ordination between multiple policy and market activities.

\subsection{Operational capacity}

A key proposition emerging from the network governance literature is that open and inclusive policy networks, although fluid in membership and often difficult to institutionalise, contribute to effective policymaking because they are able to absorb complexity and can be more resourceful and resilient in delivering outcomes than closed and exclusive networks (Bovens et al, 2001; Koppenjan and Klijn, 2004). Policy-makers trying to effect a transition to a low carbon economy must deal with political, technological and market uncertainties that require they act within existing 
sector-specific networks, as well as across different networks linked by novel biofuel policy agendas.

\subsection{Foresight capacity}

The ability of governments to look forward and anticipate is often doubted, and the attribution of myopia brought about by electoral timetables or media cycles is common. Understanding the capacity to anticipate potential political as well as private enterprise 'hold-up' problems is important, independent of an ability to resolve them. Even amidst pervasive uncertainty, effective policy-making requires a capacity to identify policy targets for the distant future. The governance of sustainability may require, and recognise 'known unknowns' to map a future path for policy.

\subsection{Reflection capacity}

Even if the long-term policy goal is fixed, reflection - as a map-reading exercise - requires governments to monitor continually where they have come from, where they are going, and how they might get there. This dimension encompasses the faculty for detecting problems with current policy settings (Deutsch, 1963; Argyris and Schon, 1978), and the ability to learn both cross-nationally and longitudinally in order to respond to evidence of failings. The capacity of policy-makers to avoid 'muddling through' when faced with existing policies identified as ineffective and/or unpopular (Koppenjan and Klijn, 2004) is an important element of the steering mechanism available to governments. The extent to which the policy-making system as a whole has access to, and can utilise, institutions that allow current policies to be 
critically examined, to look back to recover historical lessons and scan the international horizon for alternative policy change options, to maintain or restore travel towards far-distant goals, is constitutive of policy capacity.

\section{Time, Biofuels Policy Design, and Policy Implementation}

In both the EU and US biofuels policy has been transformed, in under a decade, from a relatively minor aspect of energy policy into a central, economy-wide plank of energy strategy in the transport sector. Despite their dissimilarities as political systems and the dissimilar constellation of political interests in sustainability policy, both jurisdictions arrived at a shared objective, at roughly the same time, of promoting a dramatic increase in the production and consumption of biofuels in the liquid transport fuel market. This section begins by introducing EU and US biofuels policies, before analysing the capacity of biofuels policy-makers to prepare, implement and sustain biofuels policies.

The salient episodes of policy design in the two biofuels policy processes under scrutiny are the US 2007 Energy Independence and Security Act (EISA) and the EU's 2009 Renewable Energy Directive (RED) (US Senate and House of Representatives, 2007; EU, 2009, respectively). It is the ambition to increase biofuels consumption in the US, through a mandatory Renewable Fuel Standard (RFS) in the Energy Policy Act of 2005, and in the EU through voluntary targets in the 2003 Biofuels Directive (US Senate and House of Representatives, 2005; EU, 2003, respectively), that act as the proximate bases for the 2007 and 2009 policy adoptions.

Both EISA and RED impose mandates for the use of renewable fuels in transport well above current domestic production levels (biofuels are expected to 
deliver most of the $10 \%$ renewable transport fuels target in the EU by $2020 ; 36$ billion gallons in the US by 2022). EU policy does not target specific types of biofuel. US policy, however, divides the 36 billion gallon mandate explicitly between different biofuels via a, revised, RFS2. By 2015, 15 billion gallons are mandated to come from conventional biofuels delivering at least a $20 \%$ reduction in GHG emissions relative to fossil fuels. The advanced biofuel mandate rises to 21 billion gallons in $2022,{ }^{3}$ of which at least 16 billion must come from cellulosic biofuels, delivering a $60 \%$ emissions-reduction. At least 1 billion must come from biomass-based diesel delivering 50\% reductions (as must non-cellulosic advanced ethanol).

The setting of mandates in this way gives rise to two major policy consequences. First, as outlined earlier, we can already 'do' $1 \mathrm{G}$ biofuels, but technological barriers have, thus far, limited advanced biofuels' market development. Currently, about $99 \%$ of all biofuels are $1 \mathrm{G}$, despite policy support for the commercial development of advanced biofuels. ${ }^{4}$ Second, $1 \mathrm{G}$ biofuels have a number of sideeffects (elaborated on below), which advanced biofuels can help alleviate or avoid. Thus policy efforts are bifurcating: policy-makers are establishing measures to limit directly the downsides of $1 \mathrm{G}$ biofuels; whilst continuing to promote the development and marketisation of advanced biofuels. We consider later the relatively limited demand-side policy efforts, beyond establishing the mandates.

Whilst biofuels policy design sought to promote domestic policy objectives, in implementation biofuels policies have attracted the attention of non-domestic political

\footnotetext{
${ }^{3}$ In most contexts, 'advanced biofuels' are those derived from non-food or animal-feed inputs. In RFS2, 'advanced biofuels' are defined in terms of their GHG emissions reduction performance and thus include, for example, Brazilian sugarcane-ethanol.

${ }^{4}$ This figure was quoted by [details to be added if the paper is accepted].
} 
actors: international institutions like the Organisation for Economic Cooperation and Development; research institutes such as the International Food Policy Research Institute, with a focus on trade and development; and advocacy groups of non-state actors organised cross-nationally. This was manifest in the politics around the world food price spike in 2008 , which came after world biofuels production had trebled between 2000 and 2007 .

Indeed, the international scrutiny and criticism of biofuels policies is related to their entanglement with societal values such as security, environmental protection, economic development, and rural communities. It shaped the implementation politics by directing attention to the impact of biofuel production on food security and the heightened incentives to convert lands in the developing south to biofuels production. This sits alongside environmental sustainability, with efforts to model the net lifecycle energy benefit of biofuels versus conventional fossil fuels, including the land use change impacts of biofuels on GHG emissions (see, for example, Searchinger et al, 2008; Bouët et al, 2010; Edwards et al, 2010).

Although these models are subject to controversy, they suggest to policymakers that greater environmental gains will come from advanced biofuels, whose GHG savings are larger, which avoid the food-fuel trade-off and most of which avoid land-use change effects. This reinforces the panaceaic properties assigned to advanced biofuels: they perform the function of separating incommensurable values in the policy process, assuaging opponents of $1 \mathrm{G}$ biofuels by promising that any harmful effects now will be dissipated by technological change and the development of advanced biofuels in the future.

\subsection{Value agreement capacity}


The development of biofuels policies in the EU and US has been underpinned by reference to three dominant drivers: energy security, climate change mitigation and rural development, underpinned by the 'renewable' nature of biofuels. The emphasis given to each has varied over time, and reflected different domestic political constituencies. A challenge for policy-makers has been to design policy capable of embracing the incommensurable values of different actors, linked to these different factors, to establish a pro-biofuels coalition.

It was accepted, when biofuels policies were being developed, that biofuels markets would be created by $1 \mathrm{G}$ biofuels, despite their potential downsides, because they were the only biofuels available immediately on any scale. Interviews with officials within the European Commission and US government departments confirmed that both see $1 \mathrm{G}$ biofuels as a 'bridge' technology: they establish a market which will then be expanded by advanced biofuels, once they are available commercially. Thus, multi-faceted biofuels policies seek to offer something to different constituencies. This is an important element in the deliberate tolerance of ambiguity of policy goals, in combination with the conscious design of market and technological uncertainty into the policy process.

Thacher and Rein (2004) provide a typology of practical solutions to managing value conflicts in policy-making such as these (see also Stewart, 2009). Value conflict is mitigated through organisational design. Through structural separation or firewalling, different public organisations involved in a policy are guardians of different values. The US and EU biofuels cases reveal a novel variant of the firewalling strategy: the policy is designed to separate conflicting values intertemporally. In both cases, there are short term goals of increasing the production 
and consumption of $1 \mathrm{G}$ biofuels, alongside longer term goals for advanced biofuels. The advanced biofuels policy element thus functions as a superordinate policy goal to describe the overall direction of travel, with $1 \mathrm{G}$ biofuels presented as a necessary bridging step to an advanced biofuels economy.

Energy security has had a dominant place in US policy discourse. Following the 9/11 terrorist attacks President Bush Jr, in every subsequent State of the Union Address, called for the US to reduce its dependence on imported oil. EU biofuels policy references energy security, but the emphasis is more on diversifying imports, in terms of fuel types and source countries. Instead, EU biofuels policy emerged in the early 2000s, following a decade where the EU had positioned itself as a global leader in climate change politics (see, inter alia, Oberthür and Pallemaerts, 2010; Wurzel and Connelly, 2010). US policy referenced climate change mitigation, for example in the later State of the Union Addresses of President Bush Jr, but one senior public servant in Washington revealed that only recently could climate change be spoken of publicly as important for US policy.

Rural development enters biofuels policy discussion via the production of the (primarily) agricultural feedstocks used to produce biofuels, and the frequently rural location of biofuels processing plants. In the European Commission, within the Agriculture Directorate General the bioenergy unit is located as part of Rural Development policy. In the US, biofuels policy is seen more overtly as part of 'traditional' agricultural policy (several interviewees referred to the role of "big ag" in ethanol policy). This is seen in RFS2 with the de facto ring-fencing of 15 billion gallons of ethanol, principally, for corn. These different interpretations of the 'rural development' biofuels policy driver are consistent with the relative importance of energy security or climate change values in EU and US policy discourse. US policy, 
with a focus on biofuels derived from domestic feedstocks, is consistent with 'security' values, exemplified by energy security. The EU focus on enhancing rural economic opportunities, meanwhile, is aligned more closely with 'harmony' values, also seen in concern for climate change (see Braithwaite, 2009, for more on the valuebalance model)

In the US, biofuels policy was also influenced, in 2005 , by a confluence of big ag and environmental concerns. In 1990, amendments to the US Clean Air Act mandated oxygenates be used in fuel to improve air quality. One oxygenate is ethanol; another is Methyl Tertiary Butyl Ether (MTBE). By 2005, concerns over groundwater pollution by MTBE led to the removal of Federal MTBE liability protection (about half of the states had already banned it or restricted its use). Further, there were concerns over possible environmental damage from oxygenates, Thus the obligation to include oxygenates in petrol in high-pollution urban areas was removed. Interviews revealed that, given this latter policy change and in response to lobbying from the corn and ethanol sectors, the 2005 Energy Policy Act introduced the RFS mandate partly to maintain policy support and a market for (corn) ethanol.

The political tensions inherent in the value conflict between rural development, energy security and climate change mitigation have been exacerbated by an uncertain market (given agricultural commodity and oil price volatility) alongside technological uncertainty about the blend wall for first generation ethanol (in the US) ${ }^{5}$ and the feasibility of industrial scale production of advanced biofuels (in the US and EU). The temporal separation of $1 \mathrm{G}$ and advanced biofuels targets in both jurisdictions, in the presence of these uncertainties, has thus set the conditions for implementation politics.

\footnotetext{
${ }^{5}$ The demand for ethanol for blending with petrol is limited by total petrol demand and the maximum permitted blend percentage.
} 
A central feature of policy in both jurisdictions has thus been that the demand side policy was enacted without coordination with supply availability and import security concerns.

\subsection{Selection Capacity}

Recent work by Patashnik (2008) on the political dynamics of major reforms offers insights into why some reforms stick and others are unpicked. In particular, reforms that endure through the implementation process typically destroy an existing policy subsystem and reconfigure the political dynamics. This insight is highly relevant to the ability to commit societal actors to a policy direction or, in our terms, selection capacity. In terms of its political salience, biofuels is a new policy domain in the EU and US, overlapping several existing policy domains with their own networks and legacies.

In the US, the EISA set out a much expanded RFS2. In the EU, the voluntary biofuels targets established in 2003 were, in the RED, replaced with significantly higher mandated targets. In both, a longer timeframe was set down for delivering the expanded mandates. The conflict between interests/actors in the biofuels processes under scrutiny were, therefore, not resolved in a single policy act, but have continued beyond initial adoption or enactment. The two-part biofuel policy design (1G/advanced) enacted in both the US and EU was a strategic move to 'select' a path in a dynamic policy system rather than a one-off choice in some classic textbook way. The promise or foreshadowing of a radically changed policy environment, notably a mass market and international industry in biofuels, has provided policy logic in the system, favouring some interests or values over others. Nevertheless, this selection 
has not determined uniquely the subsequent policy path, which instead remains open and contingent to shifts in policy preferences which arise from political competition.

There are important intertemporal dimensions in both jurisdictions in terms of selection capacity. The strategy has been to agree policy objectives in the short term, and accommodate different and conflicting values involved in biofuels expansion by legislating guides to future policy change in the advanced biofuels sector. This adoption of two separate types of biofuels policy has precipitated a distinctive implementation situation. There is a superordinate goal of a substantial biofuel component in the liquid transport fuel market, but there is limited explicit guidance over the sources of future advanced biofuels. Whilst both the EU and US are providing support for the development of advanced biofuels, several interviewees in Brussels and Washington stressed it was 'technology-neutral'. There also exist complementary superordinate constraints such as production sustainability criteria, which are perceived to constrain $1 \mathrm{G}$ biofuels more than advanced

In the EU, additional 'credit' against renewables targets is available for advanced biofuels. In the US, the RFS includes separate targets for different types of biofuel, but this is accompanied by powers granted to the Environmental Protection Agency (EPA) to reduce those targets annually, in line with expected production. Uncertainty over what industry actors are willing and able to deliver raises the question of whether, and how, this acts as a constraint on the evolution of policy, in which actors are committed to a certain policy direction. This concern is reinforced by the inclusion of this reverse gear in the policy implementation process.

Our analysis of interview data shows that, in both the US and EU the discourse of sustainability is creating tensions. Far from helping to integrate various policy objectives in the implementation phase, it is (i) adding complexity to initial 
policy design, and increasing the number of objectives, interests and players in policy implementation; and (ii) is used as a key resource by institutionally-embedded actors in existing policy legacies, to protect their autonomy against the ambitions for a coordinated implementation of the initial policy design embracing $1 \mathrm{G}$ and advanced biofuels. This is accentuated by the continued absence of significant commercial-scale production of advanced biofuels from the market.

Policy is always made under conditions of uncertainty. The uncertainties that attend biofuels policy, however, are central to selection capacity. Biofuels are valid outlets for EU and US agricultural commodities, in the context of de-coupled agricultural support policies: these 'market' drivers exist independently of 'policy' reasons. Meanwhile, mandates increase certainty for those investing in advanced biofuels technologies; but they also seek to commit future policy-makers to the values (and policies) determined in the present, consistent with Parsons' notion of 'weaving'.

\subsection{Operational capacity}

The design of biofuels policy in both jurisdictions requires flexibility and adaptation in operation, to ensure meeting longer-term targets. In the US, demand for ethanol is restricted by the blend wall. The policy response has been to seek agreement on raising the ethanol blend in petrol, to $15 \%$, for newer vehicles. Interviews indicated there are several million flex-fuel vehicles in the US, able to run on any ethanol-petrol mix, but mainly because of tax-breaks lowering purchase prices; availability of E85 ( $85 \%$ ethanol) remains limited and localised. Given the supplyside constraints discussed above, however, US policy is reaching a critical impasse. 
The blend wall, combined with improving fuel efficiency and high fuel prices, are limiting demand for ethanol; yet the limited commercial development of advanced biofuels is limiting potential supplies. This is a stark picture linked intimately to the firewalling of the two supply-side elements of US biofuels policy which, more by chance than design, reflect different segments of demand. Interviews with both US agencies and biofuels interests confirmed that the 15 billion gallons devoted to conventional ethanol in RFS2, was the maximum it was believed could be produced without significant impacts on agricultural markets and prices, rather than determined in relation to estimated current demand capacity. The EU mandate of $10 \%$ of transport fuel from renewables in 2020 is somewhat more modest than the US target. Given also that the EU mandate does not distinguish between biofuel types, it is more achievable. Countries' progress towards their individual targets, however, remain mixed at this stage (European Commission, 2011).

Policy implementation has also stimulated international trade in biofuels although sometimes in unexpected ways. Although shortfalls in US advanced biofuels production could be met by, for example, imports of Brazilian sugarcane-ethanol, currently ethanol is being exported by the US - including to Brazil. Reasons include the blend wall limiting domestic US demand; and poor Brazilian cane harvests and high sugar prices, pushing more of the harvested cane for sugar production. That said, Brazil has been exporting ethanol to California, which demands greater GHG emissions reductions than most US ethanol delivers. Brazilian imports help ensure adequate supplies of ethanol to blend in petrol - even though high ethanol prices are limiting demand for E100 at the pump.

The EU mandate was always understood to require biofuel imports to fulfil. As a result, EU policy has implications for global supply chains. This leads to a key 
transnational factor influencing domestic policies: the presence of WTO trade rules. Whilst biofuels policies give rise to a wide range of trade concerns (see, inter alia, Swinbank, 2009), our focus in the present paper is sustainability criteria, especially those developed by the EU. ${ }^{6}$ These seek to ensure the biofuels consumed in the EU deliver significant life-cycle GHG emissions reductions, whilst avoiding damage to vulnerable soils and ecosystems. Interviews with senior Commission officials confirmed the EU criteria were developed with WTO rules expressly in mind. Moreover, (Ackrill and Kay, 2011) find the process of their negotiation was consistent with the WTO Technical Barriers to Trade Agreement (TBTA), helping to limit the chances trade disputes subsequently.

The development of sustainability criteria has led to innovations in governance, notably the involvement of international commodity Roundtables concerned with sustainability. Economic and civil society actors, such as the Roundtable on Sustainable Palm Oil and Bonsucro work to ensure local feedstock production is consistent with EU criteria, via certification and verification processes (Verdonk et al 2007; Mol, 2010; van den Hombergh, 2008). Such direct engagement between governments and Roundtables is key, where the alignment of Roundtable certification schemes with importer government standards sets the biofuels trade policy agenda.

Although international trade in biofuels connects domestic markets and involves non-state actors and the private sector, this does not extend to transnational politics influencing domestic biofuels policies. The principal inter-governmental body is the Global Bioenergy Partnership (GBEP). Interview data from Brussels,

\footnotetext{
${ }^{6}$ US policy includes GHG emissions reductions thresholds, and sustainability criteria applicable to all feedstock production, from any source country. That said, the text distinguishes between, for example, federal and non-federal lands, suggesting a domestic orientation dominating their initial design.
} 
Washington and Brasilia, however, reveal very little transnational political impact on domestic policies in this forum. Instead, for example, it provides a forum for countries to 'learn about' each other's jurisdictions, policies, the repertoires of instruments and methods, rather than representing an epistemic community (Haas, 1992). The domestic politics are so competitive it seems that this 'soft' power is attenuated and does not redistribute existing power in the policy system

Thus our interviews reveal evidence of transnational political networking activity by policy-makers, but in political terms the influence of this work is attenuated. Identifying a lack of operating capacity at the transnational scale, particularly in political terms in the form of inter-governmental influence, is an important finding. One interpretation is that at the present stage of the development of biofuels policy, the construction of domestic operating capacity continues to be of paramount importance. Moreover we may assume that, a priori, this is less challenging politically than constructing operational capacity on a transnational scale. Considering the co-ordinating mechanisms to implement policy, and how these have left it susceptible to fragmentation through sustainability concerns, brings the initial policy design into analytical focus; notably rural development, energy security, and GHG emissions reduction policy objectives managed intertemporally. This strategy has required the bridge between the two stages, of $1 \mathrm{G}$ and advanced biofuels, to be credible for co-ordinated implementation. Without this, spillovers may arise between the different temporal dimensions of policy, and values conflict as their incidence is distributed among different policy legacies that might have an interest in biofuels policy. With continuing criticisms of the downsides of $1 \mathrm{G}$ biofuels, the continued failure to bring significant volumes of advanced biofuels to market, and (in 
the US), further questions over demand constraints, the bifurcation built into biofuels policy design is magnified in implementation.

\subsection{Foresight Capacity}

To adapt a distinction in March (1978), policy-making always takes place in an environment of uncertainty about the consequences of action, but importantly also in an environment in which there is uncertainty about future preferences. The study of policy processes, over many decades, has served to query empirically the assumption that policy preferences are stable over time, consistent, and exogenous to policy actions. Instead preferences are often vague, unstable and inconsistent.

Both US and EU transport biofuels policies exist in a wider policy context, framed by the three drivers of policy outlined earlier. Thus biofuels policy may be sheltered from disruptions by being embedded within wider policy agendas. Equally, biofuels policies may be vulnerable, not only to direct disruptions, but to challenges to one or more of those wider agendas, the values they represent, and the ability of biofuels to help deliver on those wider agendas.

Biofuels do replace fossil fuels and they do represent rural economic opportunities. A great deal of attention currently is focused on the ability of different biofuels to deliver GHG emissions reductions, relative to fossil fuels. One difficulty is that different combinations of feedstock and technology pathway deliver different GHG emissions performances. One reason why EU and US policies place such emphasis on the development of advanced biofuels, is because they are perceived to deliver better GHG emissions reductions performances than almost all $1 \mathrm{G}$ biofuels, also reducing or avoiding their other downsides, as discussed earlier. 
One dimension of the biofuels debate embodies both of these concerns: indirect land use change (ILUC). Because biofuels markets overlap agricultural commodity markets, land markets, and energy markets, shifts in supply and/or demand in one market will, via price transmission, affect supply and/or demand in other markets. Specifically, biofuels policies raise the supply and demand for agricultural feedstocks. Ceteris paribus, this will increase prices in those commodity markets as a result of which, if ILUC occurs, land elsewhere will be brought into agricultural use to produce those commodities. In so doing, however, the first cultivation will release carbon stored in both the soil and any biomass present.

In theory, ILUC should be included in any GHG emissions calculations of the biofuels feedstock production that triggered the price rise that encouraged farmers elsewhere to change their land-use decisions. In practice, there are considerable problems, most notably that it cannot be observed directly. It can only be estimated by the economic modelling of those market linkages. This contributes to ILUC being a highly contested concept. Views range from one extreme, as revealed by interviews in Washington and Brasilia, where policy-actors refused to accept the occurrence of ILUC to a degree worth reflecting in policy, through to a position based on the precautionary principle, that we do not understand ILUC adequately, so we should place a moratorium on biofuels production.

Ultimately, as a result of concerns such as these with $1 \mathrm{G}$ biofuels, policymakers' foresight capacity has led to policies with long-term directions and endpoints defined in terms of developing successful advanced biofuels industries, whilst dealing with the downsides of $1 \mathrm{G}$ biofuels in the meantime. Issues such as determining the scale of ILUC in different settings, seek to protect the broad direction of travel of biofuels policy during the early years of travel towards far-distant goals. 


\subsection{Reflection Capacity}

Can inconsistencies between policy-as-designed and policy-as-implemented be identified and corrected? Can lessons be learned from past experiences and/or from experiences in other countries? Policy-makers need to be able to reflect on policies as implemented, making changes where necessary to maintain forward movement in the general direction of broad goals, even if they are implicit and unquantified. A credible commitment to longer term targets for biofuels lies at the heart of implementation politics, which may require changes to policies or policy settings along the way.

Our data reveal that the feedback processes from policy design to subsequent policy changes are not straightforward; they are an uncertain and volatile mixture of positive and negative. There is evidence of policy layering (Streeck and Thelen, 2005; Mahoney and Thelen, 2010) in design; for example, biofuels policy overlaps with, though is much broader in scope than, the agricultural policy domain. But policy layering in design needs to be complemented by analysis of its consequences in implementation. For example, biofuels utilise feedstocks that are also food for humans or feed for animals, but do market linkages mean biofuels create unacceptable impacts on food prices? If so, how can biofuels policy be adapted, to maintain the general direction of travel, but address unanticipated and unwelcome gaps between policy as designed and policy as implemented?

The interaction between different legacies and new interests can be observed in the lack of institutionalisation and co-ordination between the two parts of the design, for $1 \mathrm{G}$ and advanced biofuels, in the implementation phase. The biofuels cases are suggestive of the particular difficulties of joining up government in the new 
governance of sustainability. The two part policy designs that were enacted in the US and the EU immediately introduced a number of bureaucratic players in implementation. In the EU several Commission Directorates-General were involved: Energy (ENER), Mobility \& Transport, Environment, Climate Action and Agriculture; in the US there was Energy, Agriculture, EPA and State. The emergence of new international organisations, such as GBEP, provide a forum for discussion that is more constructive and progressive than traditional international intergovernmental organisations; whilst non-state actors, notably commodity Roundtables, have a novel and key role in policy implementation.

In both the EU and US, despite the policy mandates, we observe a biofuel policy bifurcation between an increasingly path-dependent $1 \mathrm{G}$ component and a still incoherent, uncertain and contested advanced component. In terms of technological uncertainty and policy implementation, the biofuels policy case is affected by uncertainty about parameters within existing technologies (such as blend walls) as well as uncertainty about technological shifts to advanced biofuels. The potential consequences of this latter shift - something anticipated in existing policy design for biofuels policy-making is so profound as to affect adversely the institutionalisation of advanced biofuels policy.

A major challenge for biofuels policies moving forward is trying to balance the supply and demand sides, given the uncertainties faced on both sides. The state of technology limits the supply of advanced biofuels. Technology, however, also limits demand. This is seen most clearly in the US, with debate over the blend wall, negotiations over raising the permitted ethanol blend percentage in petrol to $15 \%$ for newer cars, and questions over the ability of the fuel transportation and distribution network to carry biofuels. 
One advantage of biofuels initially was that consumers did not have to change behaviour. The mandates led to fuel companies blending biofuels into petrol and diesel, whilst consumers just carried on doing what they always did. The ongoing expansion of biofuels production, however, had challenged directly consumption and consumer behaviour. Direct impacts have involved, for example, the potential consequences for misfueling, if E15 is put into vehicles suitable only for E10. As a result, in response to the EPA permitting E15, the Renewable Fuels Association (RFA) has produced a guide for petrol retailers (RFA, 2012). By offering guidance on the retailing of E15, the RFA seeks to ensure the spread of its sale and thus help to push back the blend wall. Such efforts will also help reassure consumers about the chances of damaging their vehicles by misfueling. Furthermore, in the face of wider concerns over biofuels at a time of high oil prices, the RFA is leading efforts to publicise the benefits of US ethanol as a means of helping limit rises in petrol prices. ${ }^{7}$

In Brazil, consumers in the late 1980s who had bought ethanol-fuelled cars found themselves without fuel when a combination of low oil prices and high sugar prices saw ethanol production collapse. Partly against this backdrop when, from 2009, poor cane harvests and high sugar prices affected ethanol production, interviews revealed the Brazilian Sugarcane Producers Association and the government worked together, via local and national media, to provide information to consumers as to the optimal combinations of petrol and E100 to put in their flex-fuel vehicles for different local price combinations. This helped consumers directly, but more broadly maintained consumer support for ethanol.

There has been no such visible efforts in the EU to support biofuels, even in the face of the vocal opposition to biofuels from a range of actors, notably some

\footnotetext{
${ }^{7}$ Such as this ad: http://www.youtube.com/watch?v=_4UKPIm61VM\&feature=youtu.be
} 
international development NGOs. Instead, it is trying to avoid the occurrence of the downsides of $(1 \mathrm{G})$ biofuels. These debates, typically, fail to distinguish between the impacts of different $1 \mathrm{G}$ biofuels, let alone between $1 \mathrm{G}$ and advanced. Thus one challenge for policy-makers going forwards involves efforts to maintain consumer support for biofuels as they continue to develop the increasingly distinct biofuels policies, on the one hand improving the performance of $1 \mathrm{G}$ biofuels, on the other continuing to support the development of advanced biofuels. Co-ordination problems may well be fundamentally technical in nature rather than policy/political; but the concern of this paper is how technological uncertainty is related to policy coordination in implementation.

\section{Conclusions}

In this paper, we have used the concept of policy capacity to structure an indepth empirical study of biofuels policies in the EU and US; an early and influential case which tests the ability of policy-makers to 'map and weave' a path to a low carbon economy. The credibility of policy-makers commitment to this future path lies at the heart of our analysis. The different dimensions of policy capacity discussed are necessary to support such an intertemporal commitment. Policy-making in the absence of such capacity is unlikely to be time consistent with the obvious corollary that is it unlikely to be successful.

Biofuels policies in the EU and US have developed significantly, at about the same time, during the last decade. As we have traced their development, significant differences have been observed, as well as similarities. In the implementation phase, land use change, sustainability and food security concerns have pushed both US and 
EU policy in a convergent direction, as policy-makers seek to contain the negative consequences of expanded $1 \mathrm{G}$ biofuels production. The capacity of policy-makers to prevail in such early implementation struggles is essential to the credibility of the long-term commitment to a biofuels economy.

The nature of implementation politics has varied across the two cases. Crucially, EU debates have, from the design phase, been located in a wider climate change (c.f. US) strategy. Indeed, we can see separate policy frames at the design phase in US and EU in terms of deeper cultural values: EU desire to be 'green' diplomatic leader in the world during the time of the Bush administration and the assertion of deep and distinctive 'European' values; as does the energy security concern in the US tapping into older notions of self-sufficiency. Yet the continued contestation of biofuel policy in the implementation phase in both US and EU, especially from 2008 with high and volatile food prices, can be observed in increasingly common problems of policy co-ordination, particularly in managing the 'bridge' between the two types of biofuel policy, for $1 \mathrm{G}$ and advanced biofuels, with attendant consequences for implementation politics.

In the EU, the phased introduction of policy has seen the introduction of the RED in 2009, sustainability criteria in 2010, and discussion over land-use change through 2011 and 2012. 2012 will see the first of a series of two-yearly reports on the implementation of the RED. This will test the Reflection Capacity of the EU. That said, EU policy is sufficiently flexible that its biofuels target can be met, albeit mainly with $1 \mathrm{G}$ biofuels. In the US, the failure to develop significant production of advanced biofuels, especially cellulosic, represents a serious threat to the ability of the US industry to produce the desired volumes of biofuel types by 2022; whilst the blend wall and the limited availability of higher ethanol-blend petrol and cars to use it 
represents a serious limit to market demand. Here, Reflection Capacity is being seriously challenged - and may require a response which questions the entire biofuels policy capacity of the US.

\section{References}

Ackrill, R., \& Kay, A. (2011). EU Biofuels Sustainability Standards And Certification Systems - How To Seek WTO-Compatibility. Journal of Agricultural Economics, $62,551-564$.

Adger, W. N., \& Jordan, A. (Eds.). (2009). Governing Sustainability. Cambridge: Cambridge University Press.

Argyris, C., \& Schon, D. (1978). Organisational Learning: A Theory of Action Perspective. Reading MA: Addison Wesley.

Bakvis, H. (2000). Rebuilding Policy Capacity in the Era of the Fiscal Dividend: A Report From Canada. Governance, 13, 71-103.

Bakvis, H., \& Aucoin, P. (2005). Public Service Reform and Policy Capacity: Recruiting and Retaining the Best and the Brightest? In M. Painter, \& J. Pierre (Eds.), Challenges To State Policy Capacity (pp. 185-204). Basingstoke: Palgrave.

Bouët, A., Dimaranan, B. V., \& Valin, H. (2010). Modelling the Global Trade And Environmental Impacts Of Biofuel Policies. Discussion Paper 01018, International Food Policy Research Institute, Washington, DC.

Bovens, M., T'Hart, P., \& Peters, B. G. (2001). Success and Failure In Public Governance: A Comparative Analysis. Cheltenham: Edward Elgar.

Braithwaite, V. (2009). The Value-Balance Model and Democratic Governance. Psychological Inquiry, 20, 87-97. 
Davis, G. (2000). Policy Capacity and the Future of Governance. In G. Davis, \& M. Keating (Eds.), The Future Of Governance (pp. 230-243). St Leonards: Allen \& Unwin.

Deutsch, K. W. (1963). The Nerves of Government: Models Of Political Communication And Control. New York: Free Press

Dror, Y. (2001). Capacity to Govern: A Report to the Club of Rome. London: Frank Cass.

Edwards, R., Mulligan, D., \& Marelli, L. (2010). Indirect Land Use Change From Increased Biofuels Demand: Comparison Of Models And Results From Marginal Biofuels Production From Different Feedstocks. EUR 24485 EN, Joint Research Council Scientific and Technical Report JRC 59771. Luxembourg: Publications Office of the European Union.

EU. (2003). Directive 2003/30/EC of the European Parliament and of the Council of 8 May 2003 on the promotion of the use of biofuels or other renewable fuels for transport (biofuels Directive). Official Journal of the European Union L123 (pp. 42-46), Brussels.

EU. (2009). Directive 2009/28/EC of the European Parliament and of the Council of 23 April 2009 on the promotion of the use of energy from renewable sources and amending and subsequently repealing Directives 2001/77/EC and 2009/30/EC (renewable energy Directive). Official Journal of the European Union L140 (pp. 16-61), Brussels.

European Commission. (2011). Recent Progress In Developing Renewable Energy Sources And Technical Evaluation Of The Use Of Biofuels And Other Renewable Fuels In Transport. Commission Staff Working Document SEC(2011)130 final, Brussels. 
Haas, P. (1992). Epistemic Communities and International Policy Coordination. International Organization, 46, 1-35.

Howlett, M., \& Lindquist, E. (2004). Policy Analysis and Governance: Analytical and Policy Styles In Canada. Journal of Comparative Policy Analysis, 6, 225-249.

Kavalov, B. (2004). Biofuels Potentials in the EU. EUR 21012 EN. Brussels: European Commission Joint Research Centre.

Koppenjan, J., \& Klijn, E.-H. (2004). Managing Uncertainties in Networks: A Network Approach to Problem Solving and Decision Making. London: Routledge.

Mahoney, J., \& Thelen, K. (2010). A Theory Of Gradual Institutional Change. In J. Mahoney, \& K. Thelen (Eds.), Explaining Institutional Change: Ambiguity, Agency, and Power (pp. 1-37). New York: Cambridge University Press.

March, J. (1978). Bounded Rationality, Ambiguity, and the Engineering of Choice. The Bell Journal of Economics, 9, 587-608.

Mol, A. P. J. (2010). Environmental Authorities and Biofuel Controversies. Environmental Politics, 19, 61-79.

Oberthür, S., \& Pallemaerts, M. (Eds.). (2010). The New Climate Policies of the European Union. Brussels: VUB Press.

Painter, M., \& Pierre, J. (2005). Unpacking Policy Capacity: Issues and Themes. In M. Painter, \& J. Pierre (Eds.), Challenges To State Policy Capacity: Global Trends And Comparative Perspectives (pp. 1-18). Basingstoke: Palgrave.

Parsons, W. (2004). Not Just Steering but Weaving: Relevant Knowledge and the Craft of Building Policy Capacity and Coherence. Australian Journal of Public Administration, 63, 43-57.

Patashnik, E. (2008). Reforms at Risk. Princeton NJ: Princeton University Press. 
RFA (2012). E15 Retailer Handbook. Renewable Fuels Association. Available at: http://ethanolrfa.3cdn.net/62e6e5d16c896ef941_tzm6vusyl.pdf

Sabatier, P. (Ed.). (1999). Theories of the Policy Process. Boulder CO: Westview Press.

Sabatier, P., \& Jenkins-Smith, H. (1993). Policy Change and Learning. Boulder CO: Westview Press.

Searchinger, T., Heimlich, R., Houghton, R., Dong, F., Elobeid, A., Fabiosa, J., Tokgoz, S., Hayes, D., \& Yu, T.-H. (2008). Use of US Croplands for Biofuels Increases Greenhouse Gases Through Emissions From Land Use Change. Science, $319,1238-1240$.

Stewart, J. (2009). Public Policy Values. Basingstoke: Palgrave

Streeck, W., \& Thelen, K. (2005). Introduction. In W. Streeck, \& K. Thelen (Eds.), Beyond Contimity: Institutional Change in Advanced Political Economies (pp. 139). Oxford: Oxford University Press.

Swinbank, A. (2009). EU Policies on Bioenergy and their Potential Clash with the WTO. Journal of Agricultural Economics, 60, 485-503.

Thacher, D., \& Rein, M. (2004). Managing Value Conflict in Public Policy. Governance, 17, 457-486.

US Senate and House of Representatives. (2005). Energy Policy Act. Public Law 10958 , 109th Congress.

US Senate and House of Representatives. (2007). Energy Independence and Security Act. Public Law 110-140, 110th Congress.

Van den Hombergh, H. (2008). Multistakeholder Commodity Roundtables: Lessons From Civil Society Engagement. Summary report of workshop results and recommendations. Amsterdam: Roundtable on Sustainable Biofuels. 
Verdonk, M., Dieperink, C., \& Faaij, A. (2007). Governance of the Emerging Bioenergy Markets. Energy Policy, 35, 3909-3924.

Wurzel, R., \& Connelly, J. (Eds.). (2010). The European Union As A Leader In International Climate Change Politics. London: Routledge 